IV. HABSBURGISCHE HERRSCHAFTSGEBIETE

\author{
IV. I DAS KÖNIGREICH UNGARN
}

SZABOLCS SERFŐZŐ

\title{
Themen und Formen der Repräsentation Maria Theresias in Ungarn
}

In der neueren Forschung zur visuellen Repräsentation Maria Theresias wurden zahlreiche Aspekte des Themas bearbeitet, der Frage nach den regionalen Unterschieden wurde jedoch bislang relativ wenig Aufmerksamkeit gewidmet. ${ }^{1}$ Diese Fragestellung bezieht sich hauptsächlich darauf, welche regionalen Differenzen in der Repräsentation der Herrscherin aufzuzeigen sind und welche thematischen und formalen Spezifika sich in ihrer Imagebildung in den verschiedenen Provinzen der Habsburgermonarchie manifestieren. Ebenso relevant ist die Frage, in welchem Zusammenhang diese Akzentunterschiede mit den verschiedenen Herrschaftstiteln der Monarchin, bzw. mit den diversen Kreisen der Adressaten stehen.

Ziel des vorliegenden Beitrags ist es, diese Fragen am Beispiel des Königreichs Ungarn zu thematisieren und einen Überblick über die Schwerpunkte in der Repräsentation Maria Theresias in Ungarn, bzw. als Königin von Ungarn zu geben. Der ungarische Königstitel war bekanntlich der wichtigste Titel Maria Theresias, dementsprechend war ihre Repräsentation in dieser Rolle äußerst vielfältig, sowohl im profanen als auch im sakralen Bereich. Auf Basis einer Erhebung der Bildquellen zum Thema der visuellen
Repräsentation der Regentin in Ungarn lässt sich feststellen, dass die ungarische Krönung Maria Theresias in Preßburg am 25. Juni $1741 \mathrm{im}$ Zentrum dieser reichen politischen Ikonografie steht.

\section{Das ungarische Krönungskleid Maria Theresias}

Die Krönung Maria Theresias in Preßburg lief nach dem Ritual der frühneuzeitlichen ungarischen Krönungszeremonien ab. ${ }^{2}$ Ein bedeutsames Element dieser Tradition war es, dass der zu krönende Herrscher am Tag der Krönung „ungarisch“ gekleidet war, ${ }^{3}$ er trug also die ungarische Adelstracht und wurde auch auf den sogenannten Krönungsporträts in diesem Kleid wiedergegeben. ${ }^{4}$ Der Brauch, die habsburgischen Herrscher auf diese Weise für die Krönung zu inszenieren, hatte offenbar eine tiefere symbolische Bedeutung: Das Anlegen der ungarischen Adelstracht für die Preßburger Krönungszeremonie kann als eine Art Rollenspiel verstanden werden. Das Kleid verdeckte den Tatbestand, dass der gekrönte Herrscher Repräsentant einer fremden Nation und Dynastie war. Für die Zeit der

1 Das Thema wurde aus regionaler Sicht am Beispiel von Ungarn und Vorderösterreich bearbeitet, vgl. Galavics 1984; Hertel 2016b. Vgl. in diesem Band Linsboth, Böhmen \#\#.

2 Vgl. Hertel 2016a.

3 Dózsa 2001. Nach einem Inventar der ungarischen Reichskleinodien von 1551 bestand der mittelalterliche Krönungsornat der ungarischen Könige aus einer liturgischen Tracht ähnlichen Kleidungsstücken (Mantel, Alba, Stola, Cingulum usw.), wie sie auch im Krönungsornat der römisch-deutschen Kaiser vorkamen (vgl. Kruppa 2005). Diese waren aber um die Mitte des 16. Jahrhunderts größtenteils vernichtet bzw. verloren gegangen. Dieser Umstand dürfte der Grund dafür sein, dass ab der Thronbesteigung Maximilians II. im Jahre 1563 die Habsburger in ungarischer Adelstracht gekrönt wurden.

4 Buzási 1991; Buzási 2018; Polleroß 2010. 
Krönung wurde der Herrscher durch die ungarische Adelstracht symbolisch selbst zu einem Ungarn. ${ }^{5}$ Er wurde damit zum Mitglied der ungarischen adeligen Stände, wodurch er das Image eines guten ungarischen Herrschers verkörpern konnte. Die ungarische Kleidung war damit ein wichtiges Element der symbolischen Legitimation der habsburgischen Herrscher als Könige von Ungarn. ${ }^{6}$

Die männlichen Vorgänger Maria Theresias wurden in der ungarischen adeligen Männerkleidung gekrönt, deren charakteristische Teile der Dolman (eine mit Schnüren verzierte Jacke), der darüber getragene Mente (ein mit Pelz verbrämter langer Mantel) und der mit Federn verzierte Hut waren. Das Krönungskleid Maria Theresias wurde nach dem Modell der weiblichen ungarischen Adelstracht gestaltet (vgl. Taf. 6). ${ }^{7}$ Über das Aussehen dieses Kleides vermerkte das Zeremonialprotokoll bei der Beschreibung des Preßburger Krönungszugs folgendes: „Ihro allerhöchst gedacht königl. May. sassen alleine in ged. Chaisen und waren in hungarischer Kleydung, wovon der Rock von weissen Crissette durch aus mit Gold gesticket, und sehr reich en dessein mit Rubin, Schmaragden, und Brillanten besetzet. Die Ermel, und das Fürtuch waren von denen kostbarsten niederländischen Spitzen von einem Stuck, und anstatt deren Bänder waren ged. Ermel mit ungemeinen kostbahren brillanten, und Perlen-Schnüren zusammen gebunden, so ware auch das Brust-stuck von weissen Crisset mit Gold reich durch aus gesticket, und auf Hungarische Arth mit unzahlbahren Perlen und kostbahren Steinen besetzet, und mitten voran hatten Ihro May. das kostbare mit denen grössten Brillanten besetzte Portrait Ihro königl. Hoheit dero Herrn Gemahls, so allerhöchst dieselben vor dero Vermählung von Ihro königl. hoheit zu schenken bekommen, angehefftet, und die Schnür-Brust aber anstatt einer Gürttel etliche Schnüre derer gleich- und grössesten orien- talischen Perlen, so mann nur sehen kann. Das Haupt ware zur bevorstehenden königl. Crönung also zwar zu bereitet, daß ausser der zierlichsten Haar-Krauße dasselbe nicht mit dem mindesten Geschmuck, oder Aufputz versehen gewesen, umd den Halß aber hatten Ihro May. den kostbahrsten Geschmuck. “8

Viele Elemente des Krönungskleides Maria Theresias entsprechen tatsächlich der ungarischen adeligen Frauenkleidung der Frühen Neuzeit. Ein repräsentatives Beispiel dafür ist ein Damenkleid (um 1750) in der Sammlung des Ungarischen Nationalmuseums aus dem Besitz der Familie Majthényi (Abb. 118). Charakteristische Eigenarten dieses Kleides sind der weit geschnittene Rock, die lange Spitzenschürze, die weiße Bluse mit weiten Ärmeln, des Weiteren das Korsett, das über der Bluse getragen wurde. Das für die Preßburger Krönung angefertigte Galakleid Maria Theresias enthielt alle diese Gewandteile, wurde jedoch in einigen Details der gebräuchlichen zeremoniellen Frauenkleidung angepasst. So wurde beispielsweise der Rock mit einer Schleppe versehen, die im Krönungszug von der Obersthofmeisterin Gräfin Fuchs-Mollard gehalten wurde. ${ }^{9}$ Gabriel Anton Graf Erdődy, Bischof von Eger, erhielt das Kleid nach der Krönung, um es zu einem geistlichen Ornat umarbeiten zu lassen; die Schleppe wurde zu einem Pluviale umgestaltet (vgl. Taf. 8). Wie die Krönungsporträts Maria Theresias vermuten lassen, wurde wahrscheinlich auch der Rock mit einem Reifrock unterstützt, um einen schönen Fall des schweren, mit reicher Metallfadenstickerei verzierten Stoffes zu erzielen. Der Reifrock war nämlich ein unerlässlicher Teil der zeitgenössischen weiblichen Hofkleidung. Die Bluse und die Schürze wurden anstatt aus dem gewöhnlichen weißen Leinenstoff aus repräsentativerer Spitze gefertigt.

Ein ähnliches Beispiel für einen weiblichen Krönungsornat nach ungarischer Art vor der Zeit Maria Theresias ist

5 Dieser Brauch war kein Sonderfall in Mitteleuropa: Im 17. Jahrhundert wurden in Polen die Mitglieder der schwedischen Wasa-Dynastie sowie 1697 und 1734 die Kurfürsten von Sachsen in polnischer Adelskleidung, in Kontusz und Zupan, gekrönt und auch in dieser Tracht porträtiert. Vgl. Serfőzo 2017a, 109; Rożek 1987.

6 Maria Theresia war schon beim Einzug in Preßburg am 20. Juni 1741 auf ungarische Art gekleidet. Sie und ihr Gefolge reisten von Wien bis Petronell in Trauerkleidung aufgrund des Todes Kaiser Karls VI. Bei dem Empfang an der ungarischen Grenze bei Wolfsthal erschienen jedoch alle „in ganz gefärbter groß Gala“, die Königin selbst in einem „ungarischen Kleid“ (,habitu Ungarico“). Vgl. HHStA, OMeA, ZP 18, fol. 193r; Wienerisches Diarium, 28. Juni 1741; Gábor Kolinovics, Nova Ungariae Periodus, Buda: Typis Regiae Universitatis $1790,158$. Im 17. Jahrhundert haben die habsburgischen Herrscher regelmäßig auch bei der böhmischen Krönung ungarische Adelstracht als Zeichen ihres ungarischen Königstitels getragen. So war z. B. Leopold I. 1656 für die Prager Krönung „ungarisch gekleidet“, Kaiser Ferdinand trug aber „seine gewöhnliche teutsche Claidung“, vgl. HHStA, OMeA, ZP 1, S. 595.

7 Im 18. Jahrhundert war es nicht immer selbstverständlich, dass eine Herrscherin bei feierlichen Anlässen in Frauenkleidung gekleidet wurde. So trugen z. B. Zarin Elisabeth und Katharina die Große oft die grüne Uniform des Garderegiments der russischen Armee, wie z. B. die letztere bei ihrem Einzug zu Pferd in Moskau am 9. Juli 1762. Auf den Gemälden von Georg Christoph Grooth und Vigilius Eriksen wurde sie in diesem Kleid porträtiert.

8 HHStA, OMeA, ZP 18, fol. 276v. Ich danke Sandra Hertel für die Transkription.

9 Ebd., fol. 278r: „Allerhöchst gedacht Ihro Königl. Mayt. wurden von dem Cubiculariorum Regalium Magistro aus dem Wagen bedienet, und die Frau Obrist Hofmeisterin trugen den Schlepp des Rocks nach.“ 


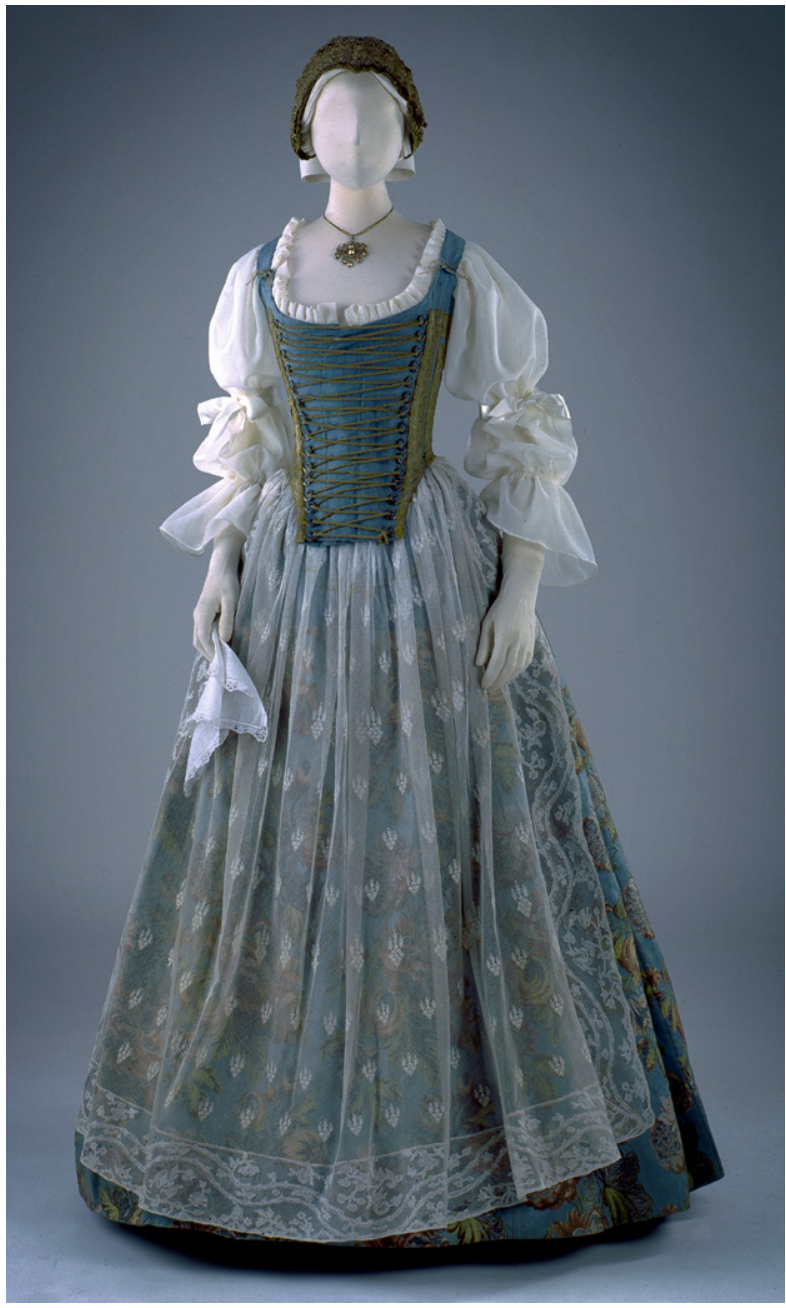

Abb. 118: Ungarisches Damenkleid, um 1750 (MNM, T.1935.109)

in Ungarn nicht bekannt: In den Beschreibungen der ungarischen Königinkrönungen lassen sich Hinweise darauf finden, dass diese aus dem Haus Habsburg in der Frühen Neuzeit immer in "deutscher Kleidung“, das heißt in ge- bräuchlicher Hoftracht, gekrönt wurden. ${ }^{10}$ Das Krönungskleid Maria Theresias nach Vorbild der ungarischen weiblichen Adelstracht war also eine Innovation und galt als wirksame Versinnbildlichung des ungarischen Königstitels Maria Theresias. ${ }^{11}$

\section{Staatsporträts im ungarischen Krönungskleid}

Anlässlich ihrer Krönungen wurden die Könige von Ungarn regelmäßig im ungarischen Krönungskleid auf Gemälden und Kupferstichen porträtiert. Solche Bildnisse sind von König Ferdinand III. und allen seinen Nachfolgern erhalten geblieben. Auch unter den Staatsporträts Maria Theresias bilden jene Bildnisse eine selbständige Gruppe, die sie als Königin von Ungarn im ungarischen Krönungskleid mit den ungarischen Krönungsinsignien (Mantel, Krone, Reichsapfel und Zepter) darstellen. Diese Krönungsporträts spielten in der Repräsentation Maria Theresias in Ungarn eine besonders wichtige Rolle. Wir haben Kenntnis von über 50 ganz- und halbfigürlichen Exemplaren dieses Porträttyps auf dem Gebiet des Königreichs Ungarn, was zeigt, dass in den 1740er- und 1750er-Jahren die ungarischen Auftraggeber eine deutliche Präferenz für diesen charakteristischen Bildtypus hatten. ${ }^{12}$

Der ursprüngliche Bestimmungsort dieser Porträts, ihre Auftraggeber sowie die Namen der Maler sind nur selten überliefert, jedoch sind uns mehrere gut dokumentierte Fälle bekannt, welche die Beliebtheit des Bildtypus in Ungarn, sowohl in öffentlichen Räumen als auch in adeligen Residenzen beweisen. So bestellte etwa der Preßburger Stadtmagistrat 1742 beim dort ansässigen Maler Daniel Schmidely ein repräsentatives Porträt Maria Theresias für die Ratsstube des Rathauses, das sie im ungarischen Krönungskleid mit den ungarischen Krönungsinsignien zeigt. ${ }^{13}$ Gleichfalls 1742 ist ein Auftrag von Peter Binder von Sachsenfels, Se-

10 Vgl. z. B. HHStA, OMeA, ZP 4, fol. 22v.

11 Die Umstände der Herstellung des Kleides sind nicht näher bekannt. Die einzige uns bekannte relevante Quelle in dieser Hinsicht ist der Bericht der Ungarischen Hofkammer über die Handwerkerkosten der Preßburger Krönung, darunter die Kosten des Krönungskleides der Königin (3000 fl.), die aus der - von den Komitaten bezahlten - „Landtagssteuer“ (Taxa dietalis) gedeckt wurden. Vgl. FHKA, Hoffinanz Ungarn Akten, 16. Dezember 1743, pag. 344: „Die Coronationis Regiae Habito - 3000 fl. (ex fundo taxa diaetalis).“

12 Von den früheren habsburgischen Herrschern sind solche Bildnisse nur in geringerer Zahl erhalten geblieben. Es ist bemerkenswert, dass im Gegensatz zu den Porträts Maria Theresias im ungarischen Krönungsornat in Ungarn die Bildnisse der Königin im böhmischen Krönungsornat in Böhmen viel weniger verbreitet sind. „Bei den Einzeldarstellungen scheint die ungarische Herrschaft der Habsburger viel häufiger vertreten zu sein als die böhmische." (Polleroß 2010, 64.) Es ist auch bemerkenswert, dass in Kroatien kein Porträt Maria Theresias im ungarischen Krönungskleid bekannt ist.

13 Serfőző 2017a, 109. Das Bild war Teil einer Porträtgalerie von habsburgischen Herrschern im ungarischen Krönungskleid im Preßburger Rathaus. Ebenfalls war ehemals eine Serie von Kaiserporträts im Ratssaal des Alten Wiener Rathauses angebracht. Vgl. Polleroß $2006,65$. Aus der Preßburger Porträtgalerie ist auch das Bildnis Karls VI. im ungarischen Kleid erhalten geblieben (Johann Jakob Matern di Cilano, 1728 [GMB, A 135]). Das Porträt von Kaiser Leopold I. ist nur archivalisch belegt: 1678 wurden aus der Preßburger Stadtkasse 17 fl. an Georg Stockhammer für das Bild gezahlt. Vgl. Fidler 1997, 242. 
nator zu Sibiu (Hermannstadt), zu einem ähnlichen Bildnis für das dortige Rathaus bei Veit Balthasar Henning in Wien nachweisbar. Das Bild wurde zum Andenken an die Huldigung einer Delegation der Stände von Siebenbürgen vor Maria Theresia am 1. Jänner 1742 angefertigt. Nach der Dedikationsschrift nahm Binder als Repräsentant der sächsischen Nation daran teil. ${ }^{14} 1753$ malte der Wiener bürgerliche Maler Johann Baptist Glunck für den Ratssaal des Rathauses in Sopron (Ödenburg) im Auftrag des Bürgermeisters Leopold Artner ebenfalls ein lebensgroßes Porträt der Königin im ungarischen Krönungskleid. ${ }^{15}$ Neben den Rathäusern der königlichen Freistädte in Ungarn wurde Maria Theresia oft auch auf Staatsporträts in Amtsgebäuden dezidiert als Königin von Ungarn dargestellt, so etwa im Ratssaal der Ungarischen Hofkanzlei in Wien, im Oberlandesgericht (Curia Regia) in Pest sowie in den Komitatshäusern (Sitz der Verwaltung des Komitates) in Győr (Raab), Miskolc und Szolnok. ${ }^{16}$ Repräsentative Porträts Maria Theresias im ungarischen Krönungskleid sind auch in adeligen Residenzen in Ungarn belegt wie etwa in den Schlösser Esterházy in Eszterháza und Pápa oder im Schloss Festetics in Keszthely. ${ }^{17}$ Ein besonderer Fall ist schließlich das Bildnis, das ehemals im sogenannten Maria-Theresien-Zimmer im Schloss Grassalkovich in Gödöllő hing, jedoch 1945 verlorenging. Antal Grassalkovich, Präsident der ungarischen Hofkammer, empfing das Herrscherpaar im August 1751 in seinem Schloss zu Gödöllő. Das genannte Porträt Maria Theresias, das sie im ungarischen Krönungskleid und mit drei Kronen auf einem Tisch darstellt, hing schon 1750 in dem für die Königin mit rotem Stuckmarmor und Vergoldungen sowie einem Baldachinbett ausgestatteten Schlafzimmer. $^{18}$
Diese Varianten der Porträts Maria Theresias im ungarischen Krönungsornat lassen sich im Wesentlichen in zwei Gruppen unterteilen: Zum einen gibt es die Gruppe jener Porträts, welche die Königin mit der Stephanskrone auf dem Haupt darstellen, zum anderen jene Bildnisse, auf denen die Krone auf einem Konsoltisch neben ihr liegt. Nach der Körper- und Handhaltung lassen sich diese Bildnisse in einige weitere Untergruppen einordnen, die sowohl in ganz- wie auch halbfigürlichen Varianten existieren.

Zur erstgenannten Gruppe gehören fünf ganzfigurige Staatsporträts. Eines darunter ist das lebensgroße Bildnis Maria Theresias, das der Wiener Kammermaler Johann Peter Kobler 1751 für das Audienzzimmer des Preßburger Schlosses malte. Für das qualitätvolle Bild und sein Gegenstück, das Porträt Franz Stephans als Feldherr (ohne kaiserliche Insignien!) zeigt, erhielt Kobler ein Honorar von 120 Dukaten aus der Privatkasse Maria Theresias. ${ }^{19}$ In fast allen Details stimmen diese beiden Werke Koblers mit jenen Porträts des Herrscherpaares überein, die 1771 ebenfalls im höfischen Auftrag für das Audienz- oder Lothringerzimmer der Innsbrucker Hofburg angefertigt wurden. ${ }^{20}$ Ein kleinformatiges $(47,5 \times 35 \mathrm{~cm})$ Gemälde in der Sammlung der Elisabethinen in Klagenfurt, das aus dem Nachlass der Erzherzogin Maria Anna stammt, dürfte als Skizze zum Innsbrucker Porträt oder als „Ricordo“ (Kopie) des Gemäldes gedient haben. ${ }^{21} \mathrm{Zu}$ dieser Gruppe gehört auch das schon erwähnte, für die Ratsstube des Ödenburger Rathauses bestimmte Porträt, bzw. jenes Bildnis Maria Theresias, das das Schlossmuseum von Gödöllő 2008 aus Privatbesitz erwarb. ${ }^{22}$ Dieses letzte Bildnis weicht von den obengenannten Beispielen in zwei Details ab: Im Hintergrund ist die Szene des Krönungsrittes, bzw. rechts von der Königin das Dop-

14 Sonoc / Popa 2015; über die Audienz vgl. Wienerisches Diarium, 6. Jänner 1742.

15 Das Bild ist rechts unten signiert: „J. B. Glunckh“, vgl. Csatkai 1953, 153. Am unteren Rand des Bildes wurde neben der Signatur ein Doppelwappen angebracht, das sich als bürgerliches Wappen des Bürgermeisters Leopold Artner und seiner Frau, Maria Ertl identifizieren lässt. Zum Wappen der Familie Artner vgl. Tompos 1942, 48. Das Porträt ist seit den 1960er-Jahren im Schloss Esterházy zu Fertőd-Eszterháza aufbewahrt.

16 MNM, 2205.a (Standort seit 2002: Staatspräsidenten-Palais); Győr, Rómer Flóris Múzeum, 65.19; Miskolc, Herman Ottó Múzeum, 94.32; Szolnok, Damjanich János Múzeum, 55.44.

17 IMM, Fotoarchiv, FLT 4459 (Aufnahme vom Porträt in Eszterháza, 1896); MNM, 53.75.

18 Michael Bombardius / Johannes Tersztyánszky, Topographia Magni Regni Hungariae, Wien: Leopold Johann Kaliwoda 1750, 538; Galavics $1991,219$.

19 Serfőző 2017a, 110; Fleischer 1932, 60, Nr. 86 (siehe ebd. die Kosten für Rahmen und Vergoldung). Die zwei Porträts wurden im Zuge der Renovierungsarbeiten der Preßburger Burg in Auftrag gegeben. Vgl. Garms 2010, 590. Die Porträts des Herrscherpaares lassen sich im Bildverzeichnis der Preßburger Burg von 1781 identifizieren, als diese zusammen mit weiteren Gemälden nach Wien transportiert wurden. Vgl. Gruber 2006, 369. Die Gemälde gehörten bis 2008 zur Sammlung des KHM, bis sie dem Hofmobiliendepot übergegeben wurden.

20 ÖKT Innsbruck Hofbauten 1986, 144 (Irrtümlich bestimmt als Replik des Maria-Theresia-Porträts von Daniel Schmidely von 1742 in der Galerie der Stadt Bratislava [GMB, A 133]).

21 Kernbauer / Zahradnik 2016, 163.

22 Früher war das Gemälde im Besitz einer nicht näher bekannten italienischen Patrizierfamilie. Die venezianische Kunsthandlung Minerbi \& Co. bot das Bild 1937 dem Budapester Szépművészeti Múzeum zum Kauf an, der Antrag wurde jedoch abgelehnt (vgl. Szépűvészeti Múzeum, Archiv, Nr. 420/1937). 
pelkreuz (Patriarchenkreuz) wiedergegeben, was auf ihren 1758 von Papst Clemens XIII. verliehenen Titel der ,apostolischen Königin“ von Ungarn hinweist. ${ }^{23}$ Dies legt eine Datierung des Bildes in dasselbe Jahr nahe.

Der hohe Grad der Ähnlichkeit dieser Werke weist darauf hin, dass sie Repliken eines heute verschollenen Prototyps sind. ${ }^{24}$ Das Urbild dürfte jenes „offizielle Krönungsporträt" sein, das ehemals im Ratssaal des Wiener Palais der Ungarischen Hofkanzlei hing, bis es schließlich 1853 entfernt wurde. ${ }^{25} \mathrm{Zu}$ diesem lebensgroßen Porträt vermerkt das Mobilieninventar von 1769, dass es schon vor langer Zeit durch die Kanzlei bestellt worden war und führt auch an:

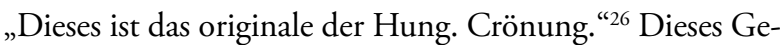
mälde dürfte kurz nach der Preßburger Krönung im Auftrag des damaligen Hofkanzlers Ludwig Batthyány gemalt worden sein, gemeinsam mit einem ebenfalls verschollenen Gemäldezyklus, der die Szenen der Preßburger Krönung Maria Theresias dargestellt hatte. ${ }^{27}$ Das Gegenstück dieses Königinporträts stellte wohl Franz Stephan als Feldherr dar und dürfte daher als Prototyp für seine Bildnisse in Preßburg und Innsbruck gedient haben.

Es ist bemerkenswert, dass das gestickte Muster des Rocks auf den Krönungsporträts sehr detailreich und minuziös dargestellt wurde: Die Motive stimmen genau mit den goldbestickten Ornamenten des Pluviales überein (vgl. Taf. 7, Taf. 9). Die Krönungsinsignien (die Krone, der Krönungsmantel, das Zepter, der Globus und das Schwert) sind ebenso wirklichkeitsgetreu abgebildet. Dieser Umstand weist darauf hin, dass diese Requisiten auf dem Prototypbild „nach dem Leben“" gemalt wurden. Eine genaue Inaugenscheinnahme der Objekte war nur drei Tage lang nach der Krönung möglich, als die Krönungsinsignien und das Krönungskleid in einem Raum der Preßburger Burg ausgestellt wurden, wo sie alle Interessierten besichtigen konnten. ${ }^{28}$ Die Krönungsinsignien wurden erst am Abend des 28. Juni 1741 durch den Kronhüter in die Krontruhe zurückgelegt. Anschließend wurde die Truhe versiegelt und an ihren Aufbewahrungsort im südwestlichen Turm der Burg zurückgebracht. Das Krönungskleid Maria Theresias wurde wahrscheinlich gleichzeitig an Bischof Erdődy übergeben.

Es liegt auf der Hand, dass der Auftrag für die Anfertigung der Bildnisse des Herrscherpaares für die Hofkanzlei dem wichtigsten Porträtmaler der Zeit, Martin van Meytens, erteilt wurde, da er und seine Werkstatt in den 1740er-Jahren mehrere Varianten dieses Porträttyps angefertigt hatten. Das einzige signierte Stück darunter ist ein Brustbild aus dem Jahre 1742, als dessen Besonderheit gilt, dass die Königin mit ihrer linken Hand ein kleines, mit Diamanten besetztes Porträtmedaillon Franz Stephans auf ihrer Brust berührt. ${ }^{29}$ Meytens fertigte mehrere weitere Varianten des Porträts Maria Theresias im ungarischen Krönungskleid an. Darunter ist ein Kniestück, das die Königin mit dem ausgestreckten linken Arm zeigt, den sie über die ungarische Krone hält, die auf einem Polster neben ihr liegt. Diese Komposition von Meytens ist in mehreren Exemplaren zu finden ${ }^{30}$ und wurde auch durch den in London

23 Der um 1115 verfassten sogenannten Hartwig-Legende zufolge verlieh Papst Silvester II. dem König Stephan I. neben der Königskrone ein apostolisches Kreuz als Zeichen dafür, dass Stephan das christliche Königreich Ungarn gründete. Damit erhielt der König auch das oberste königliche Patronatsrecht über die römisch-katholische Kirche in Ungarn. Papst Clemens XIII. erneuerte das Andenken dieser Begebenheit, indem er 1758 Königin Maria Theresia den Titel einer „Hungariae regina apostolica“ verlieh, vgl. Bahlcke 2005, 265.

24 Ebendieses Gemälde dürfte als Vorbild für die lebensgroße Zinnguss-Statue Maria Theresias gedient haben, die Franz Xaver Messerschmidt um 1765 schuf (vgl. Taf. 18). Vgl. Pötzl-Malikova 1981.

251848 wurde die Ungarische Hofkanzlei aufgelöst, von 1851 bis 1860 war das Palais Sitz des Reichsrats. 1853 wurde ein von Georg Decker gemaltes Porträt Kaiser Franz Josephs im Sitzungssaal des Palais untergebracht, dieses ersetzte womöglich das Porträt Maria Theresias. Vgl. Gecsényi 1994, 118; HHStA, Kabinettsarchiv, Reichsrat, Präsidialakten, K. 7, Nr. 94/1852.

26 UNA, Archiv der Ungarischen Hofkanzlei, Acta particularia (A 93), No. 547, fol. 307v: „In den Rath-Saal oder Raths-Stuben / An den drey Fenster-Pfeilern befinden sich drey Bilder; an einem Ihre May. der Kayser Franciscus selig Andenkens in Lebens Grösse in einer Raam von Bildhauer Arbeit und einem einfachen Adler; das zweyte Ihro May. der Kayserin unsere allergnädigste Frau in Lebens-Grösse in gleichen Raam und einfachen Adler. Das dritte eine Vorstellung des Krönungs-Landtags Anno 1741 in gleichen Raam von Bildhauer Arbeit, aber ohne Adler. N.B.: Die zwey Bilder Ihro Mayt. der Kayser und Ihro Mayt. die Kayserin (dieses ist das originale der Hung. Crönung) sind schon langen Jahren von der Kanzley beygeschaffet worden."

27 Die Porträts des Herrscherpaares und der Gemäldezyklus sind 1758 im Nachlassinventar des Kanzlers Leopold Nádasdy verzeichnet. Vgl. ebd., fol. 139r-140r. Dieser verschollene Gemäldezyklus könnte als Vorbild für die 1769 ausgeführten Gemälde von Franz Messmer und Wenzel Pohl gedient haben (vgl. Taf. 19-20, Abb. 122-125). Vgl. Galavics 1984.

28 HHStA, OMeA, ZP 18, fol. 308r.

29 Das Porträt stammt aus der Sammlung des Grafen Sternberg und ist in der Sammlung des Kunstgewerbemuseums zu Prag aufbewahrt. Vgl. AK Kupezky 2014, Nr. My9 (Signatur auf der Rückseite: „Martin de Meytens/ pinxit“). Der Porträttypus wurde durch den Pariser Kupferstecher Gilles-Edme Petit mit der Signatur: „Peint a Vienne en 1742 par Martin de Meytens“ reproduziert (ÖNB Bildarchiv, PORT_00047591_01), vgl. Polleroß 2010,68.

30 Die folgenden Gemälde gelten als Kopien des Werks von Meytens: MNM, 53.75 (Provenienz: Pápa, Schloss Esterházy); Residenzschloss 
tätigen Pieter van Bleeck in Mezzotinto reproduziert. Dieses Blatt trägt die Inschrift: „Done from an Original Drawing of Mr. Mittence [sic!] Cabinet Painter to her Hungarian Majesty, 1742. “31 Weitere Varianten des Porträts sind durch großformatige Kupferstichreproduktionen von Philipp Andreas Kilian und Georg Christoph Kilian überliefert: Beide Werke dieser Augsburger Brüder waren für ein Thesenblatt bestimmt und sind mit der Inschrift „Meytens pinxit" bezeichnet (vgl. Abb. 20). ${ }^{32}$

\section{Bildnisse Maria Theresias zu Pferd aufdem Krö- nungshügel in Preßburg}

In der Repräsentation Maria Theresias in Ungarn stellen die Reiterporträts der Königin, die sie zu Pferd auf dem Krönungshügel in Preßburg zeigen, einen weiteren wesentlichen Bildtypus dar (vgl. Abb. 26, Taf. 20). Der Ritt auf dem sogenannten Krönungshügel war ein traditionelles Ritual der ungarischen Krönung: Nach dem kirchlichen Zeremoniell im Martinsdom ritt der frisch gekrönte König in vollem Krönungsornat auf einen kleinen Hügel am Donauufer. Der Hügel bestand aus Erde, die aus allen Komitaten Ungarns zusammengetragen wurde und dadurch das ganze Land symbolisierte. Mit dem St.-Stephans-Schwert in der Rechten schlug der König in alle vier Himmelsrichtungen, als Zeichen dafür, dass er das Land gegen alle Feinde verteidigen werde. ${ }^{33}$ Maria Theresia führte dieses für eine junge Frau anstrengende Ritual fehlerlos aus, trotz des fast 40 kg schweren Krönungsornats, ${ }^{34}$ noch dazu im Damensitz. Der englische Gesandte Sir Thomas Robinson schrieb am 28. Juni 1741 mit Entzücken über das Ereignis: „The coronation on the $25^{\text {th }}$ was leste, magnificent and well ordered. The Queen was all charm; she rode gallantly up the Royal Mount, and defied the four corners of the world with the drawn sabre, in a manner to show she had no occasion for that weapon to conquer all who saw her. The antiquat- ed crown received new graces from her head, and the old tattered robe of St. Stephen became her as well as her own rich habit, if diamonds, pearls and all sorts of precious stones can be called cloths. “" ${ }^{\text {"35 }}$ Reiterbildnisse Maria Theresias in vollem Krönungsornat, mit der Stephanskrone auf dem Kopf und dem St.-Stephans-Schwert in der Rechten, meistens mit der Ansicht der Preßburger Burg im Hintergrund, wurden in den 1740er-Jahren in zahlreichen Varianten auf Medaillen sowie in Druckgrafiken und Gemälden verbreitet. Dadurch ist dieser Bildtypus geradezu ikonisch geworden: Er galt als wirksamer Ausdruck der Legitimität und politischen Kraft der Regentin. Das Bild der Frauenfigur zu Pferd, mit dem Schwert in der Hand, formulierte das Image Maria Theresias im Spannungsfeld zwischen weiblicher Identität und männlicher Herrschermacht und betonte, dass die Monarchin als legitimer Herrscher und als weiblicher König regierte. Bereits die große Zahl an entsprechenden Darstellungen könnte auch als Hinweis darauf zu verstehen sein, dass gerade in diesen Jahren der Begriff der Legitimation im Zentrum der Repräsentation Maria Theresias stand.

Es ist bemerkenswert, dass die mehr als ein Dutzend Gemälde, die diesem Typus angehören, alle Kabinettbilder im kleinen Format (um 45 x $33 \mathrm{~cm}$ ) sind und meistens das Porträt Franz Stephans zu Pferd als Gegenstück haben. Die Mehrzahl dieser Bildnisse befindet sich in Sammlungen auf dem Gebiet des historischen Ungarn, was von der besonderen Beliebtheit dieses Bildtypus in Ungarn zeugt. ${ }^{36}$ Das einzige lebensgroße Reiterporträt Maria Theresias, das sich im Schloss zu Körmend befindet, wurde wohl im Auftrag von Ludwig Graf Batthyány angefertigt, der 1737 ungarischer Hofkanzler und schließlich 1751 Palatin wurde und als solcher eine besondere Loyalität gegenüber Maria Theresia demonstrierte. ${ }^{37}$

Die herausragende Rolle dieses Bildtypus ist ein neues Phänomen in der Repräsentation Maria Theresias und findet sich nicht bei früheren habsburgischen Herrschern

Arolsen; Schloss Vizovice in Mähren. Das Motiv des Obelisken mit Palmbaum, das im Hintergrund des Bildes zu Vizovice zu sehen ist, verwendete Meytens ein paar Jahre später wieder auf dem Staatsporträt Maria Theresias, das im Zeremoniensaal zu Schönbrunn hängt.

31 MNM, TKCs 8000 (weiteres Exemplar: London, British Museum, 2010,7081.3461; Amsterdam, Rijksmuseum, RP-P-OB-17.006).

32 AK Joseph II. 1980, 329, Nr. 33; AK Maria Theresia 1980, 72, Nr. 08,03; Polleroß 2010, 68; AK Maria Theresia Schönbrunn 2017, 287, Nr. HM 21.2.

33 Hertel 2016a, 116.

34 Das im Diözesanmuseum zu Eger aufbewahrte Pluviale, das aus der Schleppe des Krönungskleids gefertigt wurde, wiegt wegen der reichen Metallfadenstickerei $18 \mathrm{~kg}$. Das Gesamtgewicht des Krönungskleides dürfte also zuletzt etwa $30 \mathrm{~kg}$ betragen haben. Der Krönungsmantel wiegt 4,7 kg, die Krone und das Schwert je um 2 kg. Gerade wegen des großen Gewichts des Krönungskleids absolvierte Maria Theresia den Krönungszug durch die Stadt nicht zu Pferde, sondern in einer offenen Kutsche. Vgl. Hertel 2016a, 117.

35 Zitiert nach: Coxe 1807, 263.

36 Der Bildtypus erschien schon zu Lebzeiten Maria Theresias im Kunsthandel, so wurden 1778 in Frankfurt am Main solche Gemälde von Meytens und Querfurth auktioniert, vgl. Ketelsen / Stockhausen 2002, 1149.

37 Serfőző 2017a, 108. 
Ungarns. Die Szene des Krönungsrittes war im 17. Jahrhundert höchstens miniaturhaft auf illustrierten Flugblättern abgebildet worden, so beispielsweise auf jenen zur Preßburger Krönung Josephs I. im Jahr 1687. ${ }^{38}$ Die einzige repräsentative Darstellung des Rittes auf dem Krönungshügel ist auf einem Relieffeld der 1602 in Prag angefertigten Rudolfinischen Hauskrone angebracht. Die selbständige Darstellung dieses charakteristischen Vorgangs der ungarischen Krönungszeremonie trat erstmals bei Kaiser Karl VI. auf: Sein Krönungsritt ist auf einer Medaille abgebildet, die 1712 anlässlich seiner Krönung zum König von Ungarn geprägt wurde. ${ }^{39}$ Zur selben Zeit schuf der 1712 zum kaiserlichen Kammerbildhauer ernannte Giovanni Stanetti eine kleinformatige Reiterstatue für die kaiserliche Schatzkammer, die Karls Ritt auf dem Preßburger Krönungshügel darstellt. ${ }^{40}$ Eine ähnliche hölzerne Reiterstatue Maria Theresias wurde um 1750 als Kunstkammerstück nach einem Kupferstich von Johann Elias Ridinger geschnitzt. ${ }^{41}$ Die Medaille, die anlässlich der ungarischen Krönung Karls VI. angefertigt wurde, könnte als Vorbild für die zwei Krönungsmedaillen Maria Theresias gedient haben, die sie zu Ross auf dem Krönungshügel darstellen. ${ }^{42}$ Diese Werke weisen auf die Existenz einer gewissen Kontinuität zwischen der politischen Ikonografie Kaiser Karls VI. und Maria Theresias hin.

\section{Staatsporträts in blauem Hofkleid und im Ornat des St.-Stephans-Ordens}

In den 1750er-Jahren scheinen die ungarischen Auftraggeber ihre Präferenz für Porträts Maria Theresias im ungarischen Krönungskleid allmählich verloren zu haben. Dies könnte auf die größere zeitliche Distanz zur Krönung zurückzuführen sein. Zu dieser Zeit wurde in Ungarn jener Bildtypus verbreitet, der - nach Gemälden von Meytens und Kobler - die Königin in einem silberbestickten blauen
Samtkleid mit weißen Spitzenärmeln und Hermelinmantel darstellt. ${ }^{43}$ Auf diesen Porträts weist nur die Stephanskrone, die auf einem Konsoltisch liegt (meistens zusammen mit der böhmischen Krone und dem österreichischen Erzherzogshut), auf den ungarischen Königstitel Maria Theresias hin. Ein solches Porträt fertigte etwa ein unbekannter Maler aus dem Umkreis von Peter Kobler um 1755 für den Festsaal des Schlosses Rimanóczy in Zsira an. Zum Anlass des kaiserlichen Besuches in den oberungarischen Bergstädten im Jahre 1751 malte der Meytens-Schüler Johann Joseph Tollenstein für den Festsaal des Kammerhofs in Banská Štiavnica (Schemnitz) ein ähnliches Bildnis. Ein drittes Beispiel stammt wahrscheinlich aus dem Schloss Bánffy in Bonchia und wurde um 1750 im Auftrag des Oberststallmeisters Graf Dénes Bánffy in der Meytens-Werkstatt gemalt. $^{44}$

Mit der Gründung des St. Stephans-Ordens im Jahr 1764 trat ein weiterer Porträttypus in der Repräsentation Maria Theresias als Königin von Ungarn auf, der die Herrscherin als Gründerin und Großmeisterin des Ordens präsentiert. Das repräsentativste Beispiel dieses Bildtypus ist das lebensgroße Porträt im Riesensaal der Hofburg zu Innsbruck, ein Werk von Wenzel Pohl aus dem Jahre 1770. ${ }^{45}$ Das Bild zeigt die Königin im weiblichen Großmeister-Ornat des Ordens: ein rotes, goldbesticktes Samtkleid mit breitem Reifrock, darüber ein grüner Samtmantel mit Hermelinfutter und der goldenen Ordenscollane. Auf dem Tisch neben ihr liegt die Stephanskrone. Zwei weitere Bildnisse stellen Joseph II. ebenso im Großmeister-Ornat des Ordens, bzw. Kaiser Franz Stephan im kaiserlichen Krönungsornat dar. Ein ähnliches Ensemble von drei Staatsporträts wurde 1766 im Festsaal des königlichen Palais zu Buda/Ofen angebracht. In diesem Jahr wurden auch drei lebensgroße Porträts Maria Theresias, Franz Stephans und Josephs II. auf Befehl der Königin durch den kaiserlichen Bildergalerie-Inspector Johann Martin Rausch von Wien nach Buda transportiert. ${ }^{46}$ Nach einer Tuschzeichnung von

38 Etényi 2012; Gyulai 2015.

39 Soltész / Tóth / Pálffy 2016, 187, Nr. 178, vgl. in diesem Band Telesko, Krönungsmedaillen, \#\#.

40 Die Statue, die wahrscheinlich aus Holz geschnitzt wurde, ist nicht erhalten geblieben und sie ist auch nicht in den Inventarien der Schatzkammer aus dem Jahre 1750 und 1773 identifizierbar. Die Existenz der Statue ist archivalisch belegt: Im Jänner 1755 wurde dem Bevollmächtigten des 29 Jahre zuvor verstorbenen Stanetti, Johann Bernhard Sedlmayr, 1200 Gulden bezahlt. Die Summe galt als Zahlungsrückstand gegenüber Stanetti für die Statue, die er für die kaiserliche Schatzkammer angefertigt hat, vgl. FHKA, KZAB 251 (Assignationsbuch für 1755), fol. 17v.

41 Mraz / Mraz 1980, 166 (Abb.).

42 Soltész / Tóth / Pálffy 2016, 214-218, Nr. 217-228.

43 Für die Analyse dieses Hofkleides vgl. in diesem Band den Beitrag von Johannes Pietsch, \#\#.

44 MNM, 54.1.

45 Fleischer 1932, 137, Nr. 630; Gödölle 2014, 105.

46 Zimmermann 1903, LXIV, Nr. 19378, Nr. 17-19. 


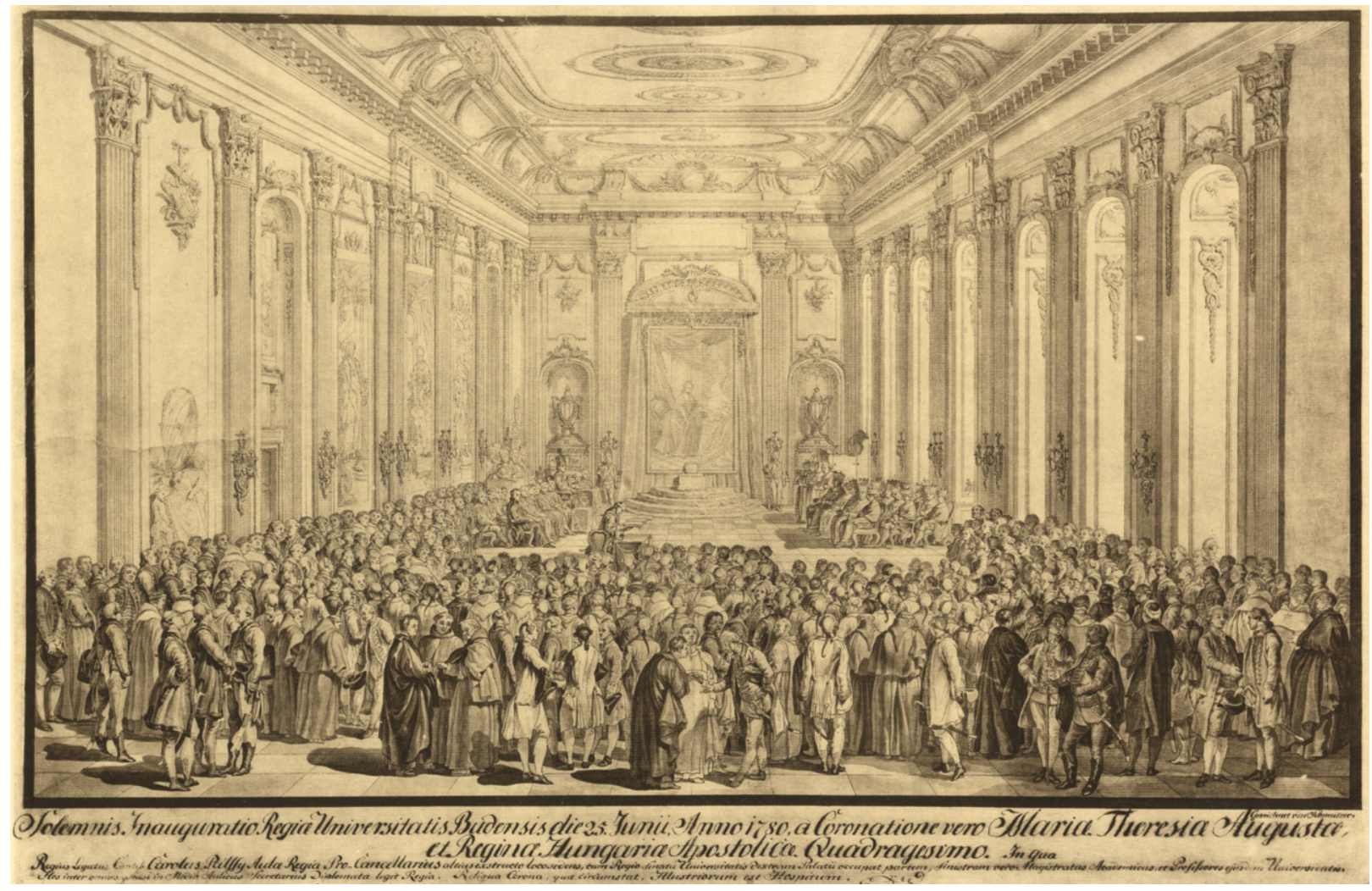

Abb. 119: Jacob Matthias Schmutzer, Eröffnung der königlichen Universität im Palais zu Buda am 25. Juni 1780 (Szalay / Czobor 1897-1901, Bd. 2, Tafel LXX)

Jacob Matthias Schmutzer, die die Eröffnung der königlichen Universität im Palais zu Buda am 25. Juni 1780 zeigt, hingen die drei Porträts an der östlichen Wand des Saals und stellen die Königin und Joseph II. als Großmeister(in) des St.-Stephans-Ordens dar (Abb. 119). Kaiser Franz Stephan hingen war im Großmeister-Ornat des Ordens vom Goldenen Vlies porträtiert. ${ }^{47}$

Es ist jedoch bemerkenswert, dass die Bildnisse Maria Theresias als Großmeisterin des St.-Stephans-Ordens relativ wenig verbreitet waren. Eine Ursache dafür ist einerseits, dass nach dem Tod Franz Stephans im Sommer 1765 die Königin die Großmeisterwürde an Joseph II. übergab, andererseits aber auch, dass ab dieser Zeit Witwenporträts der Kaiserin dominierten. Auf diesen Witwenporträts trägt die
Königin in der Regel das mit Brillanten besetzte Großkreuz des Ordens; nicht zuletzt die dargestellte Stephanskrone weist auf die ungarische Königswürde hin. ${ }^{48}$

\section{Maria Theresia als Königin von Ungarn in der Druckgrafik der 1740er-Jahre}

Die ungarische Krönung Maria Theresias als Ereignis von großer politischer Bedeutung fand in den zeitgenössischen Medien große Resonanz. Der Verlauf der kirchlichen und weltlichen Zeremonie wurde intensiv medial rezipiert und der Öffentlichkeit der Habsburgermonarchie sowohl schriftlich als auch visuell bekannt gemacht. ${ }^{49}$ So erschien

47 Die drei Staatsporträts sind nach der Übersiedlung der Universität nach Pest im Jahre 1784 verlorengegangen. Die Tuschzeichnung Schmutzers wurde 1945 in der Universitätsbibliothek Budapest vernichtet. Sie wurde in guter Qualität reproduziert in: Szalay / Czobor 1897-1901, Bd. 2, Tafel LXX. Auf der Zeichnung sind einige Charakterzüge der Bildnisse gut erkennbar, die eine Identifizierung des Porträttyps ermöglichen: Auf dem Bild links ist die Collane des Ordens vom Goldenen Vlies zu erkennen, auf dem Porträt in der Mitte Halsband und Halskette Maria Theresias, die auch auf dem Innsbrucker Bildnis zu sehen sind, und schließlich der breite Kragen des Mantels des St.-Stephans-Ordens auf dem Porträt Josephs II. an der rechten Seite. Nach der Tuschzeichnung war das Königreich Ungarn im Festsaal auch mittels Wappen repräsentiert: über dem Gesims waren das österreichische und das ungarische Wappenschild gemalt, bzw. die Wappen der vier sogenannten Kron- oder Nebenländer von Ungarn (Dalmatien, Kroatien, Slawonien und Siebenbürgen) in kleinerem Maßstab.

48 Gödölle 2014, 111, Anm. 58.

49 Zur Medialisierung der Krönung vgl. Hertel 2016a, 117. 


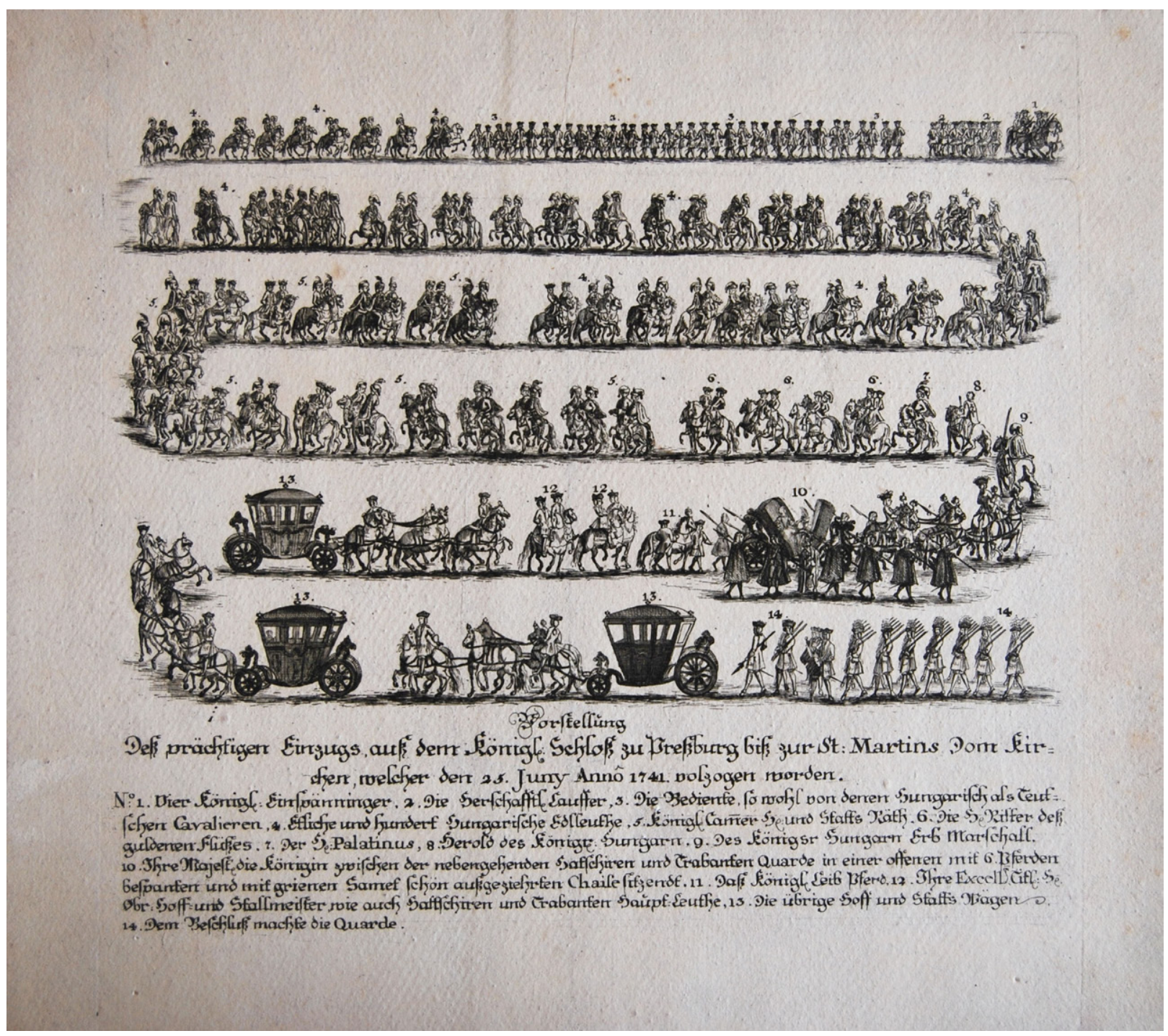

Abb. 120: Krönungszug Maria Theresias in Preßburg vom Schloss zum Martinsdom am 25. Juni 1741, undatiert (Debrecen, Bibliothek des Reformierten Kollegs)

beispielsweise als Anhang des Wienerischen Diarium eine ausführliche Beschreibung der Preßburger Feierlichkeiten, die später auch in Augsburg gedruckt wurde..$^{50}$ Dieser Bericht wurde von einer halbjährig in Frankfurt verlegten Zeitung übernommen und zusätzlich mit einem großformatigen Kupferstich, der die Krönung im Martinsdom und die Stephanskrone zeigt, illustriert. ${ }^{51}$

Neben der Darstellung der Erbhuldigung der niederösterreichischen Stände im November 1740 und der böh-

mischen Krönung Maria Theresias in Kupferstichserien, wurde auch über die Szenen der Preßburger Krönung eine Stichfolge angefertigt, die jedoch nur aus vier Blättern besteht. Die anonymen Kupferstiche stellen den Zug von der Burg zum Martinsdom (Abb. 120), die Krönung im Martinsdom, den Ritterschlag in der Franziskanerkirche und den Ritt auf dem Krönungshügel dar. ${ }^{52}$ Die Blätter sind wahrscheinlich die Werke des Augsburger Kupferstechers Elias Baeck, der um 1740 zahlreiche ähnliche Flugblätter

50 Ebd.

51 O. A., Relationis Historicae Semestralis Autumnalis Continuatio, Jacobi Franci historische Beschreibung der denckwürdigsten Geschichten, so sich in Hoch und Nieder Teutschland [...] vor und zwischen jüngst verflossenen Oster-Meß 1741 biß an die Franckfurter Herbst-Meß dieses lauffenden 1741 Jahrs [...] zugetragen, Frankfurt am Main: Engelhardische Erben 1741, 46-47, vgl. AK Maria Theresia 2017, 220, Nr. SH 5.6. Die Beschreibung der Krönung übernahm auch die Leipziger Chronik: Europäischer Staats-Secretarius, 67. Theil (1741), 579-596.

52 Debrecen, Bibliothek des Reformierten Kollegiums, C.1968.12; MNM, 3235, 3236 und 54.389. 
von höfischen Zeremonien anfertigte (vgl. Abb. 11). Zeichnungsstil und Typografie des Stichs über den Zug zum Martinsdom ähneln sowohl seinen signierten Flugblättern zum Leichenzug Karls VI., als auch jenen zur Erbhuldigung der niederösterreichischen Stände in Wien im Jahre 1740.53 Der Wiener Zeichner und Kupferstecher Salomon Kleiner hatte ebenfalls die Absicht, eine Serie von 18 Kupferstichen zur Preßburger Krönung zu verlegen. ${ }^{54}$ Dieses Projekt wurde jedoch nicht realisiert, möglicherweise weil Baeck mit seinen Flugblättern das mediale Interesse in Mitteleuropa an der ungarischen Krönung bereits ausgeschöpft hatte.

Unter den Ereignisbildern der Preßburger Krönung ist ein Kupferstich von Johann Daniel Herz dem Älteren, Direktor der Augsburger Kunstakademie, zu erwähnen, der den Zug Maria Theresias nach der Krönung über den Preßburger Marktplatz darstellt. ${ }^{55}$ Das großformatige Blatt $(70 \times 90 \mathrm{~cm})$ war wahrscheinlich auch für ein Thesenblatt bestimmt: Ein Exemplar dieses Stichs, das sich heute in Privatbesitz in Deutschland befindet, wurde am unteren Teil mit drei Kartuschen für Inschriften zum Thesenblatt ergänzt, die jedoch unausgefüllt blieben.

Eine großformatige Radierung $(98,4 \times 76 \mathrm{~cm})$, welche die Huldigung Ungarns vor Maria Theresia zum Thema hat, wurde vermutlich ebenfalls zum Zweck eines Thesenblattes angefertigt (Abb. 121). ${ }^{56}$ Es ist nur ein einziges Exemplar dieses Blattes bekannt, das sich im Stadtmuseum Villingen-Schwenningen (Baden-Württemberg) befindet und vermutlich aus dem dortigen Benediktinerkloster stammt. Das Bild wurde nachträglich in Öl übermalt und gerahmt. Am oberen Rand des Rahmens befindet sich ein geschnitzter, vergoldeter Giebel mit einer Kartusche, die das Monogramm „MT“ zeigt. Das Werk stellt die Königin thronend, mit Zepter in der Hand, in dem mit Perlen verzierten ungarischen Krönungskleid dar. ${ }^{57}$ Die Thronrücklehne verziert der Doppeladler mit Schwert und Zep- ter in den Krallen und einem Medaillon auf dessen Brust mit Maria Theresias Wahlspruch „Iustitia et Clementia“. Rechts huldigt ein kniender Page in ungarischer Tracht der Königin und überreicht ihr die ungarische Krone und den Reichsapfel auf einem Kissen. In der linken Hand hält er einen Säbel mit der Inschrift: „Brachium adhuc, et adhuc Herculis ensis adest“" (Sieh da den Arm und das Schwert von Herkules, die bereitliegen."), ${ }^{58}$ die hier auf die militärische Unterstützung der Königin durch die Ungarn im österreichischen Erbfolgekrieg hinweist. Hinter der Königin, auf einem Pulpit, liegt die Bibel, auf deren aufgeschlagener Seite ein Zitat aus dem zweiten Buch der Makkabäer (2. Makk 15,16) zu lesen ist: „Accipe sanctum gladium munus a Deo, in quo deicies adversarios“ („Nimm hin das heilige Schwert, das dir Gott schenkt. Mit ihm wirst du die Feinde schlagen."). Hinter der Bibel steht ein Kruzifix in Form eines Doppelkreuzes mit folgender Inschrift auf den Kreuzbalken: „In hoc signo vinces“, die auf die Kreuzesvision Konstantins verweist. Links am Bildrand ist das österreichische Wappen mit dem Erzherzogshut und einem Zitat aus dem Buch der Psalmen (Ps 111,3) zu sehen, das hier das Haus Habsburg lobpreist: „Substantia et divitiae in domo eius, et iustitia eius perseverans semper.“ („Reichtum und die Fülle wird in ihrem Hause sein, und ihre Gerechtigkeit bleibt ewiglich.").

Das Bild ist aller Wahrscheinlichkeit nach ein bislang unbekanntes Werk des Augsburger Kupferstechers Gottfried Bernhard Götz, da fast alle hier vorkommenden Motive in drei signierten Werken seiner Hand aus den Jahren 1742/1743 aufscheinen, die den Österreichischen Erbfolgekrieg thematisieren. Alle drei stellen das Brustbild Maria Theresias, von Inschriften umgeben, mit knienden ungarischen Husaren dar. Der erste Kupferstich trägt die Inschrift „Hungaria devotissima“ und der zweite das Chronogramm „CrVCIfIXVs DVX MeVs“ [1742]. ${ }^{59}$ Der dritte ist

53 BSB, VD18 12707341; Einbl. V,9 m: Höchst prächtige Leich Begängnus [...] Caroli des Sechsten [...], Augsburg 1740; Eigentliche Abbildung des prächtigen Zugs, nachdeme die Nieder Österreichische löbl. Stände [...], Augsburg 1740.

54 Galavics 1984, 65. Eine unpublizierte Tuschzeichnung über die Krönung Maria Theresias im Martinsdom, die in der Bibliothek des Institut National d'Histoire de l'Art in Paris aufbewahrt wird (Inv.-Nr. OC 81) könnte von Kleiner stammen und mit seinem Projekt in Zusammenhang stehen (vgl. Abb. 126).

55 AK Maria Theresia 1980, 76, Nr. 8.10; AK Maria Theresia Ungarn 1980, 160, Nr. 23.

56 Ich bedanke mich bei Michael Hütt, Ina Sahl und Sandra Hertel für die Hinweise zum Werk.

57 Anstatt des goldbestickten Rocks ist die Königin hier in einem ungemusterten blauen Samtrock, bzw. anstatt des ungarischen Krönungsmantels in einem Hermelinmantel zu sehen, wie auch auf dem oben erwähnten Mezzotinto von Pieter van Bleeck, das hier als Vorbild gedient haben dürfte.

58 Der Text stammt aus einem Ehrenspiegel für Joseph I., wo es als Motto zum Kapitel über Fortitudo steht. Vgl. Franz Joseph Garzaroll von Garzarolshoff, Regia virtutum serenissimo, et potentissimo Hungariae Regi Josepho I. Magni Caesaris Leopoldi I. filio [...], Wien: Voigt $1690, \mathrm{~F} 1$.

59 Wildmoser 1985, 159. Es ist hier zu bemerken, dass Maria Theresia um 1745 dem Künstler für seine Dienste einen goldenen Gnadenpfenning gab, vgl. Füssli 1779, 288. 


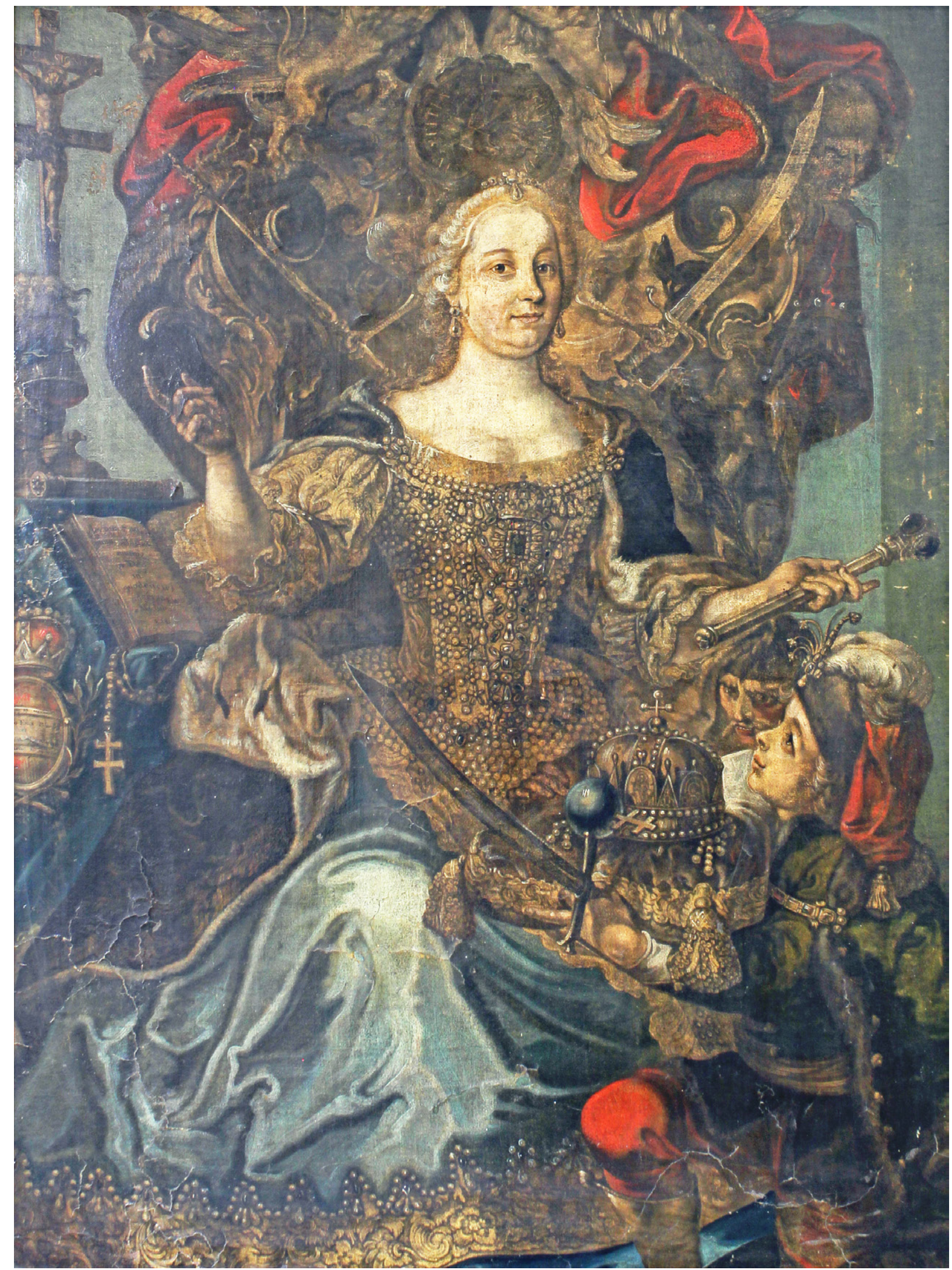

Abb. 121: Maria Theresia in Begleitung eines Pagen, Mitte 18. Jahrhundert (Villingen-Schwenningen, Franziskanermuseum, 11762) 
ein Mezzotinto, das die Herrscherin mit Doppeladler und Kriegstrophäen zeigt. ${ }^{60}$

Zusammenfassend kann festgehalten werden: In den visuellen Medien wurde das Image der Regentin als König von Ungarn in diversen Darstellungstypen formuliert und mit verschiedenen Konzepten aufgeladen. Die Reihe dieser unterschiedlichen Darstellungsformen spannt sich von den Staatsporträts und Reiterbildnissen im ungarischen Krönungsornat über Medaillen, Kupferstichfolgen und Zeremonienbilder der Preßburger Krönung bis zu den Bildnissen der Regentin als Großmeisterin des St.Stephans-Ordens. Diese diversen Bildtypen setzen die Königin effektvoll als legitime Herrscherin, Kriegsherrin, Nachfolgerin des Staatgründers König Stephan I. sowie als tugendhafte Monarchin, Mutter und Witwe in Szene.

60 MNM, 3259. 